\title{
Bilateral traumatic paralysis of abducent nerves and clivus fracture: Case Report
}

\author{
Willen Guillermo Calderon-Miranda ${ }^{1}$, Hernando Raphael Alvis- \\ Miranda $^{1}$, Gabriel Alcala-Cerra ${ }^{2}$, Luis Rafael Moscote-Salazar ${ }^{2}$ \\ University of Magdalena, Colombia \\ ${ }^{1}$ Physician, ${ }^{2}$ Neurosurgeon
}

\begin{abstract}
Clivus fractures are a rare pathology, frecuently associated tohigh power trauma. Such injuries may be associated with vascular and cranial nerves lesions. The abducens nerve is particularly vulnerable to traumatic injuries due to its long intracranial course, since their real origin until the lateral rectus muscle. The unilateral abducens nerve palsy of 1$2-7 \%$ occurs in patients with cranial trauma, bilateral paralysis is rare. We report a patient who presented bilateral abducens nerve palsy associated with a clivus fracture.

Key words: Cranial Fossa, Posterior, Skull Fracture, neurotrauma, clivus
\end{abstract}

\section{Introduction}

Fractures of the clivus are uncommon lesions, occurring in $0.55 \%$ of patients with traumatic cranial injuries. They are classified as longitudinal, transverse and oblique. Because of its medial location at the base of the skull, sometimes the diagnosis is not easy. Mortality of longitudinal fractures ranges from $67-80 \%$ and is considered to have the potential to lead to the entrapment of the vertebrobasilar vessels and direct contusion of the brain stem.

This type of injury is associated with high energy trauma. The longitudinal type has a high mortality rate, varying between $67-80 \%$, because of the occlusion of the basilar artery and/or direct trauma to the brain stem. So far there are only 12 cases reported (7 in autopsies). The abducens nerve is particularly vulnerable to traumatic injuries due to its long intracranial course, from its real origin until reach the lateral rectus muscle.

The unilateral abducens nerve palsy occurs in 1-7\% of patients with head trauma, bilateral paralysis is rare. We present a case of a patient developing bilateral paralysis of the sixth cranial nerve, bilaterally, associated with clivus fracture.

\section{Case report}

Male patient, 50 years old, right-handed, sent to our institution from a local hospital, because of moderate traumatic brain injury, due to a fall from their own height. No history records of importance. On general physical 
examination we found a hemodynamically stable man in whom, neurological examination evidenced bilateral sixth cranial nerve palsy. Brain CT scan showed a longitudinal fracture of the clivus (Figure 1). The patient is admitted to the intensive care unit with general measures and ventilatory support; in the six day, his body temperature was $39.1 \mathrm{C}$ and CSF examination was compatible with bacterial meningitis. The patient was managed with third generstion cephalosporins. The patient's antibiotic was used for 4 weeks. Is extubated in the tenth day, no complications. No commitment of the posterior circulation or alteration of the cranial nerves was documented, on ambulatory monitoring.

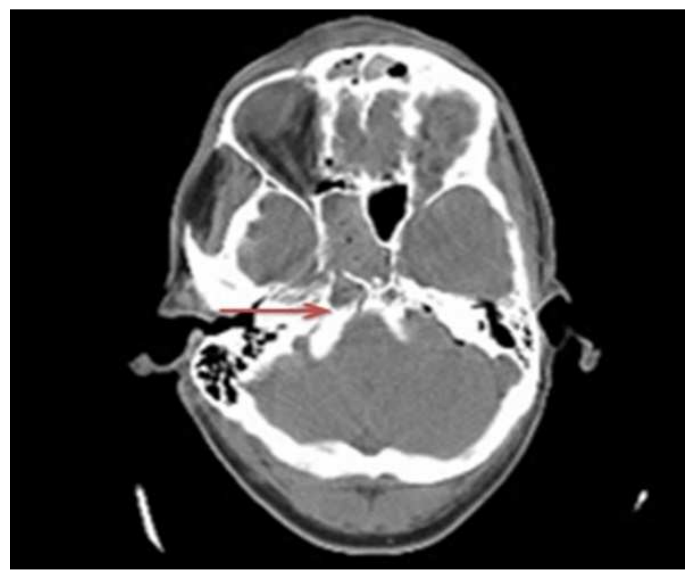

Figure 1 - Brain CT scan obtained on admission showing a longitudinal fracture in the clivus (arrow)

The clivus is considered the strongest bone, embryologically originates from the fusion of the sphenoid body to basiocciput, remaining separate up to 12 years through the sphenooccipital synchondrosis. $(1,2)$ The irrigation of the clivus is given by the meningo- hipophyseal trunk and caudally for the posterior meningeal artery, which anastomoses with the lateral clival artery. Biomechanics of clivus fractures is controversial, it has been proposed the participation of vertical, lateral and anteroposterior forces. $(3,4,5)$

The Corradino's classification divides clivus lesions in longitudinal, transverse and oblique. Longitudinal fractures are associated with increased mortality, about $67-80 \%$. High speed traumas, especially for car accidents, are related to these injuries. $(6,7,8,9)$ The risk of neurological injury is high, mainly by the proximity to brain stem structures, including the vertebrobasilar artery and cranial nerves.

The longitudinal fracture type also are linked to the basilar artery entrapment and ischemia of the brain stem. Due to its unique location in the center of the skull clivus fractures are difficult to diagnose. With standard radiography, is believed to clivus fractures are underdiagnosed, which has been overtaken by the studies of CT scan with bone window.

Mechanical forces believed to be responsible for basilar fractures involving the clivus are the sum of the outbending forces located far from the local impact that exceeds the elastic capacity of the skull and result in a fracture line that crosses the clivus. The subsequent bilateral sixth cranial nerve palsy to a clivus fracture can be explained for the relaxation of the Grüber ligament that exerts mechanical effect on the mentioned neural structures. $(10,11,12,13,14,15,16)$ 
DOI: 10.2478/romneu-2014-0070

\section{Correspondence}

Dr. Luis Rafael Moscote-Salazar, CISNEURO

Research Group, University of Cartagena,

Cartagena de Indias, Colombia e-mail:

mineurocirujano@aol.com

\section{References}

1. Hofmann E, Prescher A. The clivus: anatomy, normal variants and imaging pathology.Clin Neuroradiol. 2012 Jun;22(2):123-39

2. Ochalski PG, Adamo MA, Adelson PD, Okonkwo DO, Pollack IF.Fractures of the clivus and traumatic diastasis of the central skull base in the pediatric population.J Neurosurg Pediatr. 2011 Mar;7(3):261-7

3. Evers JJ, Vieth VV, Hartensuer RR, Raschke MM, Vordemvenne TT Management of an extended clivus fracture: a case report. BMC Res Notes. 2013 Dec 23;6:554 4. Ochalski PG, Spiro RM, Fabio A, Kassam AB, Okonkwo DO.Fractures of the clivus: a contemporary series in the computed tomography era. Neurosurgery. 2009 Dec;65(6):1063-9

5. Dashti R, Ulu MO, Albayram S, Aydin S, Ulusoy L, Hanci M. Concomitant fracture of bilateral occipital condyle and inferior clivus: what is the mechanism of injury? Eur Spine J. 2007 Dec;16 Suppl 3:261-4.

6. Yavuz C, Sencer A, Kabata? S, Imer M, Kiri? T, Unal F. [Longitudinal clival fractures: a report of three cases]. Ulus Travma Acil Cerrahi Derg. 2006 Oct;12(4):321-5. 7. Menkü A, Koç RK, Tucer B, Durak AC, Akdemir H.
Clivus fractures: clinical presentations and courses. Neurosurg Rev. 2004 Jul;27(3):194-8.

8. de Melo PM, Kadri PA, de Oliveira JG, Suriano IC, Cavalheiro S, Braga FM. Cervical epidural haematoma with clivus fracture: case report. Arq Neuropsiquiatr. 2003 Jun;61(2B):499-502.

9. Sato S, Iida H, Hirayama H, Endo M, Ohwada T, Fujii $\mathrm{K}$. Traumatic basilar artery occlusion caused by a fracture of the clivus--case report. Neurol Med Chir (Tokyo). 2001 Nov;41(11):541-4

10. Ogungbo B, Sengupta R. Traumatic fracture of the clivus and vermian contusion in a child. Br J Neurosurg. 2001 Apr;15(2):159-61.

11.Fuentes S, Bouillot P, Dufour H, Grisoli F.Occipital condyle fractures and clivus epidural hematoma. Case report. Neurochirurgie. 2000 Dec;46(6):563-567.

12.Khan N, Zumstein B. Transverse clivus fracture: case presentation and significance of clinico-anatomic correlations. Surg Neurol. 2000 Aug;54(2):171-7.

13.Corradino G, Wolf AL, Mirvis S, Joslyn J. Fractures of the clivus: classification and clinical features. Neurosurgery. 1990 Oct;27(4):592-6.

14.Joslyn JN, Mirvis SE, Markowitz B. Complex fractures of the clivus: diagnosis with CT and clinical outcome in 11 patients. Radiology. 1988 Mar;166(3):817-21

15.Kapila A, Chakeres DW. Clivus fracture: CT demonstration. J Comput Assist Tomogr. 1985 NovDec;9(6):1142-4.

16.Sights WP. Incarceration of a vertebral artery in a fracture of the clivus. J Neurosurg. 1968;28:588-591. 